\title{
Positive Role of Roof Greening Design in Haze Control in Central Plains
}

\author{
Tianshun $\mathrm{Hu}$ \\ School of Art and Design \\ Huanghe Science and Technology College \\ Zhengzhou, China
}

\author{
Yunjia Wei \\ Eastern International Art College \\ Zhengzhou University of Light Industry \\ Zhengzhou, China
}

\begin{abstract}
People have paid heavy price for the rapid development. The frequent haze in central plains is a very tough environmental problem face by people, because it not only affects people's health, but also affects the development of economy. This paper has analyzed the development, design principle and positive role of roof greening design in haze control starting from the causes of haze.
\end{abstract}

Keywords—roof greening; central plains; haze control

\section{INTRODUCTION}

The problem of haze has been in existence for a long time, but it did not cause the attention of people, until it has caused a series of social problems with more and more serious affect, and caused traffic accidents affecting economic development and people's health, thus it has become a very tough environmental problem in central plains. As the core city in central plains, Zhengzhou has become the first interview object of Ministry of Environmental Protection because of its air quality deterioration, revealing the severity of the problem.

\section{CAuses of HaZE in Central Plains}

\section{A. Influence of the Location Factors}

Central plains belong to the continental monsoon climate of North Temperate Zone which is dry with less rain and snow, as well as small wind and much dust. Thus it has caused the tiny particles to be suspended in the air, and gather constantly, at the same time, air flow speed is slow, which is prejudice to the dissipating of pollutants, making the haze problems increasingly serious.

\section{B. Impact of Energy Consumption Patterns}

Rome is not build in a day, so today's haze is not formed overnight. Coal is the main energy source in the central plains, and quite a number of enterprises haven't reach the coal emissions standards prescribed by the state. Coal-burning heating was primarily used in the past few decades, and coal consumption increased year by year, soot pollution also increased continuously, resulting in today's haze weather difficult to control.

\section{Influence of Automobile Exhaust}

With the improvement of people's living standard, the continuing expansion of city, the more and more convenient of traffic, as well as people's farther daily trip distance, people buy bars for work and tourism vacation. So car is not uncommon, as it has walked into numerous households, even one family has more than one car. While bringing convenient transportation, cars also bring about serious emissions. Although a few policies regarding emissions have been introduced, the effect is not prominent due to the uneven citizens' quality.

\section{Influence of Construction Site Dust}

Zhengzhou is the provincial capital in central plains, and currently there are more than 2000 construction sites in the city, which will not only result in long-term congestion in various major trunk roads, but also the construction waste piling in the construction site, some of the tiny particles will move under the influence of construction, and suspend in the air, affecting people's health seriously if they inhale in them.

\section{CONCEPT AND DESIGN PRINCIPLE OF ROOF GREENING DESIGN}

With the increase of haze days, the air quality in central plains is getting worse, resulting in frequent traffic accidents and closing down of highway, making transportation in our country unable to operate properly with serious impact on economic growth. What's worse, the haze cannot disperse all day long, making the traffic completely enveloped in the white haze. In addition, according to relevant reports of the hospital, the respiratory system diseases and cardiac-cerebral vascular diseases due to haze weather have also increased.

The rapid expansion of city has brought the growth of economic and social benefits, and people's living environment is also facing the feedback from the nature, namely shortage of urban land. At present, there is large gap between the per capita green area in urban area in our country and the standard as proposed by the UN ecological and environmental organization. To curb the worsening haze weather, people are trying to find other more effective ways to solve environmental problems. Vertical greening is a new technology emerging in recent years, especially the improvement of urban high-density living environment by 
roof greening design has not only saved the land area, but also increased the green landscape, and have adjusted the urban microclimate.

\section{A. Concept and Development of Roof Greening Design}

Roof greening design has a lot of names, and it is also known as the hanging garden or the fifth facade of urban architecture, which makes the greening landscape planning and design using the building roof plane. The space at the top of high-rise residential building is large, which hasn't been put into good use. The roof greening design under the condition of not changing any structure form is the most economic and effective way which is the most easy to implement. Such design of space may reduce dust, and what is more important is to improve air quality, playing a positive role in controlling haze.

At present, there are roughly two kinds of roof greening in China. One is roof greening without people going on, the other is in the form of small garden for people to play and rest. The former is suitable for smaller roof greening, while the latter is suitable for the bigger roof greening.

Roof greening can be dated back to the hanging gardens of ancient Babylon. China did not start to research the roof garden greening construction technology until the 1960s. With the development of urbanization, roof greening has caught more and more attention, as the roofs of office, hotel, residential buildings start using green design. To improve the living quality, some high-grade residential area has more perfect corresponding design of greening, making people feel like living in the park. Such community environment is favored by consumers, of which the price is higher than that of house within the same location by several thousand yuan. For example, the housing price difference of the adjacent two communities of Yongwei Dongtang Community and Xinlong Garden Community at east of South Huanghe Road in Jinshui District in Zhengzhou City is about four thousand yuan, and the housing price of Yongwei Dongtang Community is higher than that of most of the communities in east area. The reason is that the greening of Yongwei Dongtang Community is well-designed with complete supporting facilities, making people feel different environment atmosphere, indicating the importance of greening design. In recent years, the roof greening design of China's urban construction gradually rise, for example, Shanghai Jinqiao Building, Beijing Changan Hotel and Zhengzhou Haima Park community are the relatively excellent cases.

\section{B. Design Principles}

- Safety principles: Roof greening design is the work on the roof, which will lead to the increase roof floor load. The layer thickness required by the greening, the water for greening, rain water drainage, roofing waterproof as well as the corresponding problems of the stability of large plants, wind load and falling prevention all need to be taken into overall consideration. But the reality is not optimistic, as the city framework in central plains has been formed, and the roof greening problem was not taken into consideration for the existing buildings when designing and constructing them. If adding greening on them, the budget will be increased, and a series of problems about later-stage management shall be considered. Greening changes dynamically and is not achieved overnight. New requirements shall be adopted in new era. The bearing, waterproof and drainage for roof greening shall be considered for the present construction in initial design stage. And it is necessary to learn the more scientific measures and policies from the abroad, and involve the greening design concept into law, thus the roof greening design will have a more solid foundation without worrying about too much load.

- Practical principles: While designing the roof greening, the roof structure and the top plane form shall be taken into full use, to conduct reasonable greening, and select the appropriate greening content and manner to avoid massive dismantling and installation which is a waste of resources, so as to beautify the environment with the most beautiful and practical design. For example, it is good choice to create roof greening micro-landform design, featured landscape, garden design as well as the facilities and places for rest using parapet, rolling plate, roof gutter and watershed.

- Economy principle: First of all, the roof greening can only play its role when the greening area of the roof is at least fifty percent to seventy percent is guaranteed. Second, the budget shall be made reasonable while designing, and try to choose the tree species with low maintenance costs and the plants with drought resistance, heat resistance, high survival rate and strong vitality to reduce maintenance costs under the principle of rich tree species and taking the seasons and climate into full consideration.

\section{Problems Exist in Urban Greening Design}

As a new form of landscape design without taking up ground area, roof green has got more and more attention. Zhengzhou is one of the cities to introduce in roof greening technology earlier in our country. But after years of development, the green area has not achieved substantive breakthrough, even the green area proportion is decreasing compared with the expansion of city construction. According to statistics, Zhengzhou has relatively small quantity of the buildings with roof greening, and most of them are in the New Area of East Zhengzhou, Zhongyuan District and Jinshui District, of which the speed is far slower than that of demolition, let alone culture popularization. People haven't realized that location equilibrium shall be considered to control haze. In addition, among the buildings investigated, residential area accounts for the largest proportion among the buildings with roof greening design which is up to above seventy-five percent. Most of others are office environment and hotel buildings, but there is still a large distance between the overall per capita greening and the international level. 
After the comprehensive consideration, there are several reasons as below.

- Planning problem: Construction of roof greening will inevitably increase the construction cost, as for investors, they pay more attention to profits. And in the age of high-rise building prevailing, make individual residents to grow their own is bound to affect the mood of other people, allocate same area to every residents to plant can also lead to chaos in the management but, and the maintenance cost will be increased greatly to make it managed by the property management company, as these costs will be shared by each household. So developers will not necessarily take the roof greening space and public space into consideration while planning, which has resulted in the difficult to promote roof greening.

- Cost problem: Generally, the construction cost of roof greening per square meter is about four hundred yuan, which is far higher than ground greening, together with the maintenance costs shall be borne by the individual and unit, it is widely considered that the roof greening needs too much investment which they can't afford to. Greening improvement belongs to public welfare establishments which should be dominated by the government but not the individual. The current government, however, has not issued relevant laws and regulations as well as policies, which has also caused the stagnation in promotion of roof greening.

- Specification problem: From the development experience and management measures of haze of western European countries and America, roof greening design is an effective measure to improve air quality and the environment, and the developed countries have established a comprehensive norms and law in this area. Therefore, the development of roof greening in China also is bound to go this way. Roof greening needs to be included in the legal system, and needs the detailed specification and regulations to normalize and detail the roof greening design. Roof greening shall be taken into consideration while planning, designing and constructing the new buildings. Obviously, our effort in this respect is still lagged behind.

\section{Positive Role of RoOf GREENING DESIGN IN HAZE CONTROLLING IN CENTRAL PLAINS}

The developed countries, such as Germany and France, have done a lot of work and formulated the corresponding specification in order to promote roof greening design. In contract, the roof greening design in our country is still in its infancy, and there are a lot of problems need to be solved in terms of plants selection and greening form collocation, which has also highlighted the importance of roof greening and it also becomes a necessity in modern architecture development.

\section{A. Positive Effect on the Building by Roof Greening Design}

The widespread promotion of roof greening is beneficial to relieve the microclimate environment in the central plains, to make most of the heat be absorbed by plants, and it can be said that roof greening is the free air conditioning system. Roof greening design is on top of the building itself, which has reduced the influence on internal temperature by weather, reduced the internal resources consumption, at the same time, protected the top of the building, to extend lifespan of the building.

\section{B. Air Purification Effect by Roof Greening}

The main pollutant of haze is the suspended particulate matter in the air, and greening can absorb the harmful gas and impurities in the air, playing the role to purify the air. Moreover, compared with the ground greening, roof greening is located at the higher ground, which can purify air from different heights, to better play its role of regulation. Along with the development of architectural technology, the single living mode of high-rise residential building will be broken in the near future. Just imagine if computing based on the amount of population live in the high-rise building at present, set the roof of each household free for roof greening design, then the image of the whole city will be changed a lot, and the severe haze will also collapse of itself.

\section{Softening Effect of Roof Greening on Urban Space}

Urbanization has accelerated the development of highrise buildings, the reinforced concrete buildings can be seen everywhere, and the greening has played a certain role of adornment for urban space, which can reduce the cold feeling brought by the cold hard lines, having developed more recreational space for people. Urban green space affects the microcirculation of the urban ecosystem and biodiversity, making the urban landscape more diversified, more natural and more humanization.

\section{CONCLUSION}

Therefore, to achieve the efficient implementation of roof greening design, the government must be prepared to play its role of guidance, to make clear the direction of roof greening design and its sustainable development in terms of policy, making it become a part of the building structure. The second is to issue relevant technical standard of roof greening design in terms of technology, to solve a series of design problems such as waterproof, bearing, wind security of roof greening design as well as plane form selection, plant configuration and road planning. Moreover, considering from the aspect of economy, it can reduce taxes, increase support, use economic leverage, support and lead the real estate companies and property management companies to treat environmental problems and economic benefits correctly. In this way, the roof greening can be promoted more comprehensively, and can play a more positive and stable role in haze controlling in the central plains. 


\section{REFERENCES}

[1] Zhong Meiqing. Role of Roof Greening in Haze Controlling [J]. Xiandai Horticulture. 2015(16).

[2] Chen Litong. Discussion on Methods to Control Haze based on Roof Greening [J]. Xiandai Horticulture. 2015(15).

[3] Xu Zhenhua, Li Donghong. Influence on PM2.5 by Roof Greening [J]. The Journal of Hebei Forestry Science and Technology. 2013(02).

[4] Zhou Shenhua. Discussion on Role of Roof Greening in Haze Controlling [J]. Journal of Green Science and Technology. 2014(03). 